Pacific Journal of Mathematics

CONJUGATE FUNCTIONS IN ORLICZ SPACES 


\section{CONJUGATE FUNCTIONS IN ORLICZ SPACES}

\section{ROBERT RYAN}

1. The purpose of this paper is to prove the following results:

THEOREM 1. Let

$$
\tilde{f}(x)=-\frac{1}{\pi} \int_{0}^{\pi} \frac{f(x+t)-f(x-t)}{2 \tan (1 / 2) t} d t=\lim _{\varepsilon \rightarrow+0}\left\{-\frac{1}{\pi} \int_{\varepsilon}^{\pi}\right\} .
$$

The mapping $f \rightarrow \tilde{f}$ is a bounded mapping of an Orlicz space into itself if and only if the space is reflexive.

Beginning with the classical result by M. Riesz for the $L_{p}$ spaces [6; vol. I, p. 253] several authors have proved this theorem in one direction or the other for various special classes of Orlicz spaces. We mention in particular the papers by J. Lamperti [2] and S. Lozinski [4] and the results given in A. Zygmund's book [6; vol. II, pp. 116-118]. In our proof we use inequalities and techniques due to S. Lozinski $[3,4]$ to show that boundedness of the mapping implies that the space is reflexive. We use the theorem of Marcinkiewicz on the interpolation of operations [6; vol. II, p. 116] to prove that reflexivity implies the boundedness of $f \rightarrow \widetilde{f}$. Our results are more general than Lozinski's results since we use the definition of an Orlicz space given by A. C. Zaanen [5] which includes, for example, the space $L_{1}$.

Section 2 contains preliminary material about Orlicz spaces. In $\S 3$ we prove that boundedness implies reflexivity and in $\S 4$ we prove the converse.

2. Let $v=\varphi(u)$ be a nondecreasing real valued function defined for $u \geqq 0$. Assume that $\varphi(0)=0$, that $\varphi$ is left continuous and that $\varphi$ does not vanish identically. Let $u=\psi(v)$ be the left continuous inverse of $\varphi$. If $\lim _{u \rightarrow \infty} \varphi(u)=l$ is finite then $\psi(v)=\infty$ for $v>l$; otherwise $\psi(v)$ is finite for all $v \geqq 0$. The complementary Young's functions $\Phi$ and $\Psi$ are defined by

$$
\Phi(u)=\int_{0}^{u} \varphi(t) d t, \quad \Psi(v)=\int_{0}^{v} \psi(s) d s .
$$

$\Phi$ is an absolutely continuous convex function for $0 \leqq u<\infty$ and $\Psi$ is absolutely continuous and convex in the internal where it is finite.

Received January 16, 1963. Sponsored by the Mathematics Research Center, U. S. Army Madison, Wisconsin under Contract No.: DA-11-022-ORD-2059. 
If $\lim _{u \rightarrow \infty} \varphi(u)=\infty$ this internal is $0 \leqq v<\infty$. If $\lim _{u \rightarrow \infty} \varphi(u)=l$ is finite we say that $\Psi$ jumps to infinity at $v=l$.

$\Phi$ is said to satisfy the $A_{2}$-condition if there is a constant $k>0$ and a $u_{0} \geqq 0$ such that $\Phi(2 u) \leqq k \Phi(u)$ for $u \geqq u_{0}$. This is equivalent to satisfying the inequality $\Phi(l u) \leqq k l \Phi(u)$ for all sufficiently large $u$, where $l$ is any number greater than one (for a proof and further details see $[1 ; p .23])$.

The Orlicz space $L_{\Phi}=L_{\phi}(0,2 \pi)$ consists, by definition, of all measurable complex functions $f$ defined on the unit circle for which $\|f\|_{0}=\sup \int_{0}^{2 \pi}|f(t) g(t)| d t<\infty$, where the supremum is taken over all functions $g$ with $\int_{0}^{2 \pi} \Psi|g(t)| d t \leqq 1$. The space $L_{\Psi}$ is defined by interchanging $\Phi$ and $\Psi^{0}$. The Orlicz space $L_{M \Phi}$ is defined to be the set of all measurable complex functions $f$ for which

$$
\|f\|_{M \Phi}=\sup \int_{0}^{2 \pi}|f(t) g(t)| d t<\infty,
$$

where the supremum is taken over all $g$ with $\|g\|_{\Psi} \leqq 1 . L_{M T}$ is similarly defined. The spaces $L_{\varphi}, L_{\Psi}, L_{M \Phi}$ and $L_{M \Psi}$ are all Banach spaces with their respective norms when functions equal almost everywhere are identified. The spaces $L_{\Phi}$ and $L_{M \Phi}$ consist of the same functions and $\|f\|_{M \Phi} \leqq\|f\|_{\Phi} \leqq 2\|f\|_{M \Phi}$. The same is true replacing $\Phi$ by $\Psi$. The space $L_{\oplus}$ is reflexive with dual space $L_{M \Psi}$ if and only if both $\Phi$ and $\Psi$ satisfy the $A_{2}$-condition.

Two Young's functions $\Phi_{1}$ and $\Phi_{2}$ are said to be equivalent $\left(\Phi_{1} \sim \Phi_{2}\right)$ if and only if there exist positive constants $k_{1}, k_{2}$, and $u_{0}$ such that $\Phi_{1}\left(k_{1} u\right) \leqq \Phi_{2}(u) \leqq \Phi_{1}\left(k_{2} u\right)$ for $u \geqq u_{0}$. It is clear that $\sim$ is an equivalence relation and that the $\Delta_{2}$-condition is an equivalence class property. If $\Phi_{1} \sim \Phi_{2}$ then $L_{\Phi_{1}}$ and $L_{\Phi_{2}}$ consist of the same functions and the norm \|\|$_{\Phi_{1}}$ and \|\|$_{\Phi_{2}}$ are equivalent. Conversely, if $L_{\Phi_{1}}$ and $L_{\Phi_{2}}$ have the same elements then $\Phi_{1} \sim \Phi_{2}[1 ; p .112]$.

3. In this section we will show that if $f \rightarrow \tilde{f}$ is bounded then $L_{\emptyset}$ is reflexive. Let $S_{n}(f)$ denote the $n$th partial sum of the Fourier series of $f$ and write $D_{n}(t)=\sin [n+(1 / 2)] t / 2 \sin (1 / 2) t$. If $\|\tilde{f}\|_{\Phi} \leqq C\|f\|_{\Phi}$ for all $f \in L_{\oplus}$ then it follows [6; vol. I, p. 266] that $\left\|S_{n}(f)\right\|_{\Phi} \leqq A\|f\|_{\Phi}$ for all $f \in L_{\Phi}$ and all $n$, where $A$ is a positive constant independent of $n$ and $f$. Thus, the following result is ostensibly more general than the corresponding part of Theorem 1 .

Theorem 2. If $\left\|S_{n}(f)\right\|_{\phi} \leqq A\|f\|_{\varnothing}$ for all $f \in L_{\phi}$ and all $n$ then $L_{\oplus}$ is reflexive.

The proof of Theorem 2 uses the following two lemmas given by 
S. Lozinski in [3]. Lozinski proved these lemmas under more restrictive conditions on $\varphi$ than we have assumed. Nevertheless, Lozinski's proofs remain valid for the functions as we have defined them.

LEMMA 1. $(\varphi(u) / 250) \log (n / u \varphi(u)) \leqq\left\|D_{n}\right\|_{\Phi}$ for $u \varphi(u) \geqq 1$.

LEMma 2. If $\left\|S_{n}(f)\right\|_{\Phi} \leqq A\|f\|_{\Phi}$ for all $f \in L_{\emptyset}$ and all $n$ then $\left\|D_{n}\right\|_{\Phi} \leqq 2 \pi A(n+\Phi(u)) / u$ for $0<u<\infty$.

Proof of Theorem 2. Our proof is a variation of the one given by Lozinski in [4]. From Lemmas 1 and 2 we have

$$
\varphi(v) \log \frac{n}{v \varphi(v)} \leqq k \frac{n+\Phi(u)}{u}
$$

for $v \varphi(v) \geqq 1$ and $0<u<\infty . k=2 \pi A / 250$. Our immediate aim is to show that for all sufficiently large $\lambda>1$

$$
\log \left(\frac{\lambda}{2}\right) \leqq 2 k \frac{\varphi(v)}{\varphi\left(\frac{v}{\lambda}\right)}
$$

for $v \geqq v_{0}$, where $v_{0}$ depends upon $\lambda$.

For any

$$
\lambda>1, \Phi(u)=\int_{0}^{u} \varphi(t) d t>\int_{u / \lambda}^{u} \varphi(t) d t
$$

and hence

$$
\Phi(u)>\left(u-\frac{u}{\lambda}\right) \varphi\left(\frac{u}{\lambda}\right)=(\lambda-1) \frac{u}{\lambda} \varphi\left(\frac{u}{\lambda}\right) .
$$

Thus

$$
\log \frac{(\lambda-1) n}{\Phi(v)}<\log \frac{n}{\frac{v}{\lambda} \varphi\left(\frac{v}{\lambda}\right)} .
$$

By combining (3) and (1) we see that

$$
\varphi\left(\frac{v}{\lambda}\right) \log \frac{(\lambda-1) n}{\Phi(v)} \leqq k \frac{n+\Phi(v)}{v}
$$

whenever $(v / \lambda) \varphi(v / \lambda) \geqq 1$. Let $n=[\Phi(v)]=$ greatest integer in $\Phi(v)$. Then (4) becomes

$$
\varphi\left(\frac{v}{\lambda}\right) \log \left\{(\lambda-1) \frac{[\Phi(v)]}{\Phi(v)}\right\} \leqq k \frac{[\Phi(v)]+\Phi(v)}{v} \leqq 2 k \frac{\Phi(v)}{v} .
$$


For every sufficiently large $\lambda$ there exist a $v_{0} \geqq 0$ such that for $v \geqq v_{0}$

$$
1<\frac{\lambda}{2} \leqq(\lambda-1) \frac{[\Phi(v)]}{\Phi(v)}
$$

and

$$
\frac{v}{\lambda} \varphi\left(\frac{v}{\lambda}\right) \geqq 1
$$

Using (5), (6) and the fact that $\Phi(v) \leqq v \varphi(v)$ we get inequality (2) for $v \geqq v_{0}$. Since $\lambda$ can be arbitrarily large (2) implies that $\lim _{u \rightarrow \infty} \varphi(u)=\infty$ and hence that $\Psi$ does not jump to infinity. We next show that $\Psi$ satisfies the $A_{2}$-condition.

Let $\lambda$ be large but fixed and write $l=(1 / 2 k) \log (\lambda / 2)$. Then (2) states that

$$
l \varphi\left(\frac{t}{\lambda}\right) \leqq \varphi(t)
$$

for $t \geqq v_{0}$. This implies, on taking inverses, that there is a number $s_{0}$ such that for $s \geqq s_{0}$

$$
\psi(s) \leqq \lambda \psi\left(\frac{s}{l}\right)
$$

Thus

$$
\int_{s_{0}}^{v} \psi(s) d s \leqq \lambda \int_{s_{0}}^{v} \psi\left(\frac{s}{l}\right) d s=\lambda l \int_{s_{0} / l}^{v / l} \psi(s) d s
$$

or

$$
\Psi(v)-\Psi\left(s_{0}\right) \leqq \lambda l\left[\Psi\left(\frac{v}{l}\right)-\Psi\left(\frac{s_{0}}{l}\right)\right]
$$

This shows that for sufficiently large $v$

$$
\Psi(l v) \leqq 2 \lambda l \Psi(v)
$$

and hence proves that $\Psi$ satisfies the $A_{2}$-condition.

If $\left\|S_{n}(f)\right\|_{\Phi} \leqq A\|f\|_{\Phi}$ for all $f \in L_{\Phi}$ then it follows that $\left\|S_{n}(g)\right\|_{M^{\Psi}} \leqq$ $A\|g\|_{M^{W}}$ for all $g \in L_{M^{T}}$ or, equivalently, that $\left\|S_{n}(g)\right\|_{\Psi} \leqq 2 A\|g\|_{\Psi}$ for all $g \in L_{\psi}$. Since we have shown that $\Psi$ does not jump to $\infty$ we can interchange the rôle of $\Phi$ and $\Psi$ in the above argument to show that $\Phi$ satisfies the $\Delta_{2}$-condition. This proves that $L_{\Phi}$ is reflexive and completes the proof of Theorem 2.

4. In this section we prove a general result about reflexive Orlicz 
spaces which combined with the classical results of M. Riesz [6; vol. I, p. 253 and p. 266] yields the unproved half of Theorem 1 as well as the converse of Theorem 2.

THEOREM 3. Suppose that $T$ is a bounded linear operator on $L_{p}$ into $L_{p}$ for $1<p<\infty$. Then if $L_{\Phi}$ is reflexive $T$ is defined and bounded on $L_{\phi}$ into $L_{\varphi}$.

Proof. The proof consists of showing that $\Phi$ can be replaced by an equivalent function $\Phi_{1}\left(\Phi \sim \Phi_{1}\right)$ such that $\Phi_{1}$ satisfies the conditions of the Marcinkiewicz theorem on the interpolation of operations i.e. such that

$$
\int_{u}^{\infty} \frac{\Phi_{1}(t)}{t^{\beta+1}} d t=O\left\{\frac{\Phi_{1}(u)}{u^{\beta}}\right\}
$$

and

$$
\int_{1}^{u} \frac{\Phi_{1}(t)}{t^{\alpha+1}} d t=O\left\{\frac{\Phi_{1}(u)}{u^{\alpha}}\right\}
$$

for $u \rightarrow \infty$, where $1<\alpha<\beta<\infty$.

The assumption that $L_{\oplus}$ is reflexive implies that $\lim _{u \rightarrow \infty} \varphi(u)=\infty$ and hence that $\lim _{u \rightarrow \infty} \Phi(u) / u=\infty$. By $[1 ;$ p. 16] $\Phi$ is equal for sufficiently large values of $u$ to a function $M$ of the form $M(u)=$ $\int_{0}^{u} p(t) d t$ where $p$ is a nondecreasing right continuous function with $\lim _{u \rightarrow 0} p(u)=0$ and $\lim _{u \rightarrow \infty} p(u)=\infty$. Clearly $\Phi \sim M$.

By $\left[1 ;\right.$ p. 46] the function $M_{1}$ defined by $M_{1}(u)=\int_{0}^{u}(M(t) / t) d t$ is equivalent to $M$ and hence to $\Phi$. The derivative of $M_{1}^{0}$ is continuous and strictly increasing.

Since $L_{\Phi}$ is reflexive both $\Phi$ and $\Psi$ satisfy the $A_{2}$-condition. Thus both $M_{1}$ and its conjugate Young's function $N_{1}$ satisfy the $A_{2}$-condition [1; p. 23]. According to [1; pp. 26-27] this implies the existence of numbers $a, b$, and $u_{0} \geqq 0$ with $1<a<b<\infty$ such that

$$
1<a<\frac{u M_{1}^{\prime}(u)}{M_{1}(u)}<b
$$

for all $u \geqq u_{0}$. If we define $\Phi_{1}$ by

$$
\Phi_{1}(u)= \begin{cases}\frac{M_{1}\left(u_{0}\right)}{u_{0}^{a}} u^{a} & \text { for } u \leqq u_{0} \\ M_{1}(u) & \text { for } u \geqq u_{0}\end{cases}
$$

we obtain a function $\Phi_{1} \sim \Phi$ such that 


$$
1<a \leqq \frac{u \varphi_{1}(u)}{\Phi_{1}(u)} \leqq b
$$

for all $u \geqq 0$.

We next show that $\Phi_{1}$ satisfies (12) and (13) for suitably chosen $\alpha$ and $\beta$. In particular choose $\alpha$ and $\beta$ such that $1<\alpha<a \leqq b<\beta<\infty$. This is clearly possible. In what follows all of the integrals will exist as finite numbers because of (14).

Integration by parts shows that

$$
\int_{u}^{\infty} \frac{\varphi_{1}(t)}{t^{\beta}} d t=\beta \int_{u}^{\infty} \frac{\Phi_{1}(t)}{t^{\beta+1}} d t-\frac{\Phi_{1}(u)}{u^{\beta}}
$$

and

$$
\int_{0}^{u} \frac{\varphi_{1}(t)}{t^{\alpha}} d t=\alpha \int_{0}^{u} \frac{\Phi_{1}(t)}{t^{\alpha+1}} d t+\frac{\Phi_{1}(u)}{u^{\alpha}} .
$$

From (14) we obtain

$$
\int_{u}^{\infty} \frac{\varphi_{1}(t)}{t^{\beta}} d t \leqq b \int_{u}^{\infty} \frac{\Phi_{1}(t)}{t^{\beta+1}} d t
$$

and

$$
\int_{0}^{u} \frac{\varphi_{1}(t)}{t^{\alpha}} d t \geqq a \int_{0}^{u} \frac{\Phi_{1}(t)}{t^{\alpha+1}} d t .
$$

Combining (15) with (17) and (16) with (18) shows that

$$
\int_{u}^{\infty} \frac{\Phi_{1}(t)}{t^{\beta+1}} d t \leqq \frac{1}{\beta-b}\left\{\frac{\Phi_{1}(u)}{u^{\beta}}\right\}
$$

and

$$
\int_{0}^{u} \frac{\Phi_{1}(t)}{t^{\alpha+1}} d t \leqq \frac{1}{a-\alpha}\left\{\frac{\Phi_{1}(u)}{u^{\alpha}}\right\} .
$$

This shows that $\Phi_{1}$ satisfies (12) and (13). Thus by the Marcinkiewicz theorem and Theorem 10.14 of [6; vol I, p. 174] there exists a constant $K_{1}$ such that $\|T f\|_{\Phi_{1}} \leqq K_{1}\|f\|_{\Phi_{1}}$ for all $f \in L_{\Phi_{1}}$. Since $\Phi \sim \Phi_{1}$ there is a constant $K$ such that $\|T f\|_{\Phi} \leqq K\|f\|_{\phi}$ for all $f \in L_{\phi}$. This completes the proof of Theorem 3.

Statements of the standard corollaries of Theorem 1 can be found in [2].

\section{REFERENCES}

1. M. A. Krasnosel'skii and Ya. B. Rutickii, Convex Functions and Orlicz Spaces, Groningen, 1961. 
2. J. Lamperti, A note on conjugate functions, Proc. Amer. Math. Soc., 10 (1959), 71-76. 3. S. Lozinski, On convergence and summability of Fouries series and interpolation processes, Mat. Sbornik N.S., 14 (1944) 175-262.

4. On convergence in mean of Fourier series Doklady, 51 (1949), 7-10.

5. A. C. Zaanen, Linear Analysis, New York-Amsterdam-Groningen, 1953.

6. A. Zygmund, Trigonometric Series, Vols. I, II, Cambridge, 1959. 



\section{PACIFIC JOURNAL OF MATHEMATICS}

\section{EDITORS}

RalPh S. Phillips

Stanford University

Stanford, California

M. G. Arsove

University of Washington

Seattle 5 , Washington
J. Dugundu

University of Southern California

Los Angeles 7, California

Lowell J. Paige

University of California

Los Angeles 24, California

\section{ASSOCIATE EDITORS}
E. F. BECKENBACH
D. DERRY
H. L. ROYDEN
E. G. STRAUS
T. M. CHERRY
M. OHTSUKA
E. SPANIER
F. WOLF

\section{SUPPORTING INSTITUTIONS}

\author{
UNIVERSITY OF BRITISH COLUMBIA \\ CALIFORNIA INSTITUTE OF TECHNOLOGY \\ UNIVERSITY OF CALIFORNIA \\ MONTANA STATE UNIVERSITY \\ UNIVERSITY OF NEVADA \\ NEW MEXICO STATE UNIVERSITY \\ OREGON STATE UNIVERSITY \\ UNIVERSITY OF OREGON \\ OSAKA UNIVERSITY \\ UNIVERSITY OF SOUTHERN CALIFORNIA
}

\author{
STANFORD UNIVERSITY \\ UNIVERSITY OF TOKYO \\ UNIVERSITY OF UTAH \\ WASHINGTON STATE UNIVERSITY \\ UNIVERSITY OF WASHINGTON \\ AMERICAN MATHEMATICAL SOCIETY \\ CALIFORNIA RESEARCH CORPORATION \\ SPACE TECHNOLOGY LABORATORIES \\ NAVAL ORDNANCE TEST STATION
}

Mathematical papers intended for publication in the Pacific Journal of Mathematrcs should be typewritten (double spaced), and the author should keep a complete copy. Manuscripts may be sent to any one of the four editors. All other communications to the editors should be addressed to the managing editor, L. J. Paige at the University of California, Los Angeles 24, California.

50 reprints per author of each article are furnished free of charge; additional copses may be obtained at cost in multiples of 50 .

The Pacific Journal of Mathematics is published quarterly, in March, June, September, and December. Effective with Volume 13 the price per volume (4 numbers) is $\$ 18.00$; single issues, $\$ 5.00$. Special price for current issues to individual faculty members of supporting institutions and to individual members of the American Mathematical Society: $\$ 8.00$ per volume; single issues $\$ 2.50$. Back numbers are available.

Subscriptions, orders for back numbers, and changes of address should be sent to Pacific Journal of Mathematics, 103 Highland Boulevard, Berkeley 8, California.

Printed at Kokusai Bunken Insatsusha (International Academic Printing Co., Ltd.), No. 6 , 2-chome, Fujimi-cho, Chiyoda-ku, Tokyo, Japan.

\section{PUBLISHED BY PACIFIC JOURNAL OF MATHEMATICS, A NON-PROFIT CORPORATION}

The Supporting Institutions listed above contribute to the cost of publication of this Journal, but they are not owners or publishers and have no responsibility for its content or policies. 


\section{Pacific Journal of Mathematics}

\section{Vol. 13, No. $4 \quad$ June, 1963}

Dallas O. Banks, Bounds for eigenvalues and generalized convexity ........... 1031

Jerrold William Bebernes, A subfunction approach to a boundary value problem for

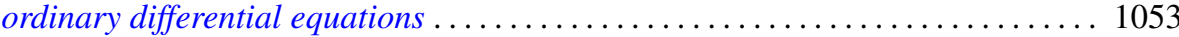

Woodrow Wilson Bledsoe and A. P. Morse, A topological measure construction . . . 1067

George Clements, Entropies of several sets of real valued functions . . . . . . . . . 1085

Sandra Barkdull Cleveland, Homomorphisms of non-commutative *-algebras . . . . . 1097

William John Andrew Culmer and William Ashton Harris, Convergent solutions of

ordinary linear homogeneous difference equations . . . . . . . . . . . . . . . 1111

Ralph DeMarr, Common fixed points for commuting contraction mappings . . . . . . 1139

James Robert Dorroh, Integral equations in normed abelian groups . . . . . . . . 1143

Adriano Mario Garsia, Entropy and singularity of infinite convolutions . . . . . . . 1159

J. J. Gergen, Francis G. Dressel and Wilbur Hallan Purcell, Jr., Convergence of extended Bernstein polynomials in the complex plane ................. 1171

Irving Leonard Glicksberg, A remark on analyticity of function algebras . . . . . . 1181

Charles John August Halberg, Jr., Semigroups of matrices defining linked operators

with different spectra ................................. 1187

Philip Hartman and Nelson Onuchic, On the asymptotic integration of ordinary

differential equations . . . . . . . . . . . . . . . . . . . . . . . . . . . . 1193

Isidore Heller, On a class of equivalent systems of linear inequalities . . . . . . . . . 1209

Joseph Hersch, The method of interior parallels applied to polygonal or multiply

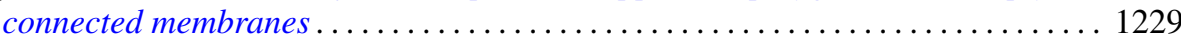

Hans F. Weinberger, An effectless cutting of a vibrating membrane . . . . . . . . . . 1239

Melvin F. Janowitz, Quantifiers and orthomodular lattices ....

Samuel Karlin and Albert Boris J. Novikoff, Generalized convex inequalities . .

Tilla Weinstein, Another conformal structure on immersed surfaces of negative

curvature.

Gregers Louis Krabbe, Spectral permanence of scalar operators

Shige Toshi Kuroda, Finite-dimensional perturbation and a representaion of

scattering operator.

Marvin David Marcus and Afton Herbert Cayford, Equality in certain

inequalities

Joseph Martin, A note on uncountably many disks .

Eugene Kay McLachlan, Extremal elements of the convex cone of semi-norms . . . . 1335

John W. Moon, An extension of Landau's theorem on tournaments . .

Louis Joel Mordell, On the integer solutions of $y(y+1)=x(x$

Kenneth Roy Mount, Some remarks on Fitting's invariants .....

Miroslav Novotný, Über Abbildungen von Mengen ............

Robert Dean Ryan, Conjugate functions in Orlicz spaces.

John Vincent Ryff, On the representation of doubly stochastic operators . . . . . . . . 1379

Donald Ray Sherbert, Banach algebras of Lipschitz functions .

James McLean Sloss, Reflection of biharmonic functions across analytic boundary

conditions with examples.

L. Bruce Treybig, Concerning homogeneity in totally ordered, connected topological space....

John Wermer, The space of real parts of a function algebra...

James Juei-Chin Yeh, Orthogonal developments of functionals and related theorems

in the Wiener space of functions of two variables......... 